\title{
Effects of tourniquet use on clinical outcomes and cement penetration in TKA when tranexamic acid administrated: a randomized controlled trial
}

\author{
Zeng Yi ${ }^{1}$, Li Yan ${ }^{3}$, Si Haibo², Wu Yuangang ${ }^{2}$, Li Mingyang ${ }^{2}$, Liu Yuan ${ }^{2}$ and Shen Bin² ${ }^{*}$
}

\begin{abstract}
Background: The role of a tourniquet is still controversial for patients undergoing total knee arthroplasty (TKA). Our current study was performed to determine whether the nonuse of the tourniquet combine with tranexamic acid (TXA) application in TKA patients with end-stage osteoarthritis would accelerate the perioperative recovery rate and provide enough cement mantle thickness for implant fixation.

Methods: In this prospective, randomized controlled trial, 150 end-stage knee osteoarthritis patients receiving TKA were divided into three groups: group A (tourniquet group), group B (non-tourniquet group), and group C (tourniquet in cementation group). All enrolled patients received $3 \mathrm{~g}$ of intravenous TXA and $1 \mathrm{~g}$ topical TXA. The primary outcomes included blood loss variables and transfusion values. The secondary outcomes included VAS pain score, inflammatory factors level, range of motion, HSS score, postoperative hospital stay, and complication. Furthermore, by using a digital linear tomosynthesis technique, tibial baseplate bone cement mantle thickness was measured in four zones based on the knee society scoring system.

Results: No significant difference was found among the three groups with regards to total blood loss, transfusion, and complication. However, patients in group B showed lower inflammatory factors levels, shorter length of hospital stay, better range of motion, and lower postoperative pain. No significant difference was found among the three groups in four zones in terms of bone cement mantle thickness.

Conclusions: For end-stage knee osteoarthritis patients, the absence of tourniquet did not appear to affect blood loss and cement penetration in TKA patients. Furthermore, less inflammation reaction and better knee function can be achieved without a tourniquet. We recommend no longer use a tourniquet in primary TKA for patients with end-stage osteoarthritis when TXA is administrated.
\end{abstract}

Trial registration: ChiCTR-INR-16009026.

Level of evidence: Therapeutic Level I.

Keywords: Total knee arthroplasty, Tourniquet, Tranexamic acid, Total blood loss, Bone cement penetration

* Correspondence: shenbin 1971@163.com

${ }^{2}$ Department of Orthopaedic Surgery, West China Hospital, Sichuan University, 37\# Guoxue Road, Chengdu 610041, People's Republic of China

Full list of author information is available at the end of the article

C C The Author(s). 2021 Open Access This article is licensed under a Creative Commons Attribution 4.0 International License, which permits use, sharing, adaptation, distribution and reproduction in any medium or format, as long as you give appropriate credit to the original author(s) and the source, provide a link to the Creative Commons licence, and indicate if changes were made. The images or other third party material in this article are included in the article's Creative Commons licence, unless indicated otherwise in a credit line to the material. If material is not included in the article's Creative Commons licence and your intended use is not permitted by statutory regulation or exceeds the permitted use, you will need to obtain permission directly from the copyright holder. To view a copy of this licence, visit http://creativecommons.org/licenses/by/4.0/. The Creative Commons Public Domain Dedication waiver (http://creativecommons.org/publicdomain/zero/1.0/) applies to the data made available in this article, unless otherwise stated in a credit line to the data. 
The tourniquet, which is widely used in total knee arthroplasty (TKA), has the proposed benefits of reducing operation time and improved visualization due to reduced bleeding. Several previous studies have proved that a tourniquet application could reduce total blood loss and create a clean blood-poor surface surgical time, which can get a long-term survival rate of cemented TKA components [1-3].

However, the role of a tourniquet is always controversial. Some potential complications have been reported in the literature, including the delayed recovery of quadriceps strength, subcutaneous fat necrosis, increased risk of infection, nerve palsy, and deep venous thrombosis, especially in obese patients $[4,5]$. Nowadays, no consensuses have been reached with regard to defining an optimal tourniquet application strategy. The application of tranexamic acid (TXA) in TKA has dramatically improved peri-operative blood management. Numerous studies have proved that TXA significantly decreases postsurgical blood loss and transfusion requirements without increasing the risk of venous thrombosis events (VTEs) $[4,6,7]$. However, seldom evaluated the effect of TXA when patients undergoing TKA without a tourniquet [8].

The purpose of our current randomized controlled study (RCT) was to determine whether intravenous and topical application of TXA in TKA patients without a tourniquet would affect: (1) intraoperative blood loss and total blood loss; (2) postoperative pain, range of knee motion and HSS scores; (3) operation time, length of hospital stay after operation and complications; (4) four zones of tibial side cement mantle thickness based on the knee society scoring system. We hypothesized that TXA combined application without a tourniquet is the best choice for patients undergoing primary TKA, which could accelerate the healing process and provide enough cement mantle thickness for implant fixation, with little or no noticeable side effect.

\section{Materials and methods}

\section{Study design and participants}

This study adheres to CONSORT guideline and was registered in the Chinese Clinical Trial Registry (date of registration: 14/8/2016, registration number: ChiCTRINR-16009026.), a first-level registration institution of the WHO International Clinical Trial Registry Platform. Approval was obtained from the Clinical Trials and Biomedical Ethics Committee of West China Hospital (No. 201302007) and all methods were carried out in accordance with relevant guidelines and regulations (Declaration of Helsinki). Written informed consent was obtained from all the participants. All the methods were conducted according to the CONSORT 2010 statement.
From May 2017 to June 2018, patients undergoing primary TKA were eligible for this trial. All the patients enrolled were diagnosed with end-stage osteoarthritis (OA). Exclusion criteria included: a history of hypercoagulation, hemophilia, deep vein thrombosis (DVT), pulmonary embolism (PE); previous surgery to the knee; bleeding disorders, platelet of bone marrow disorders; patients were diagnosed with other diseases, such as rheumatoid arthritis; patients with diabetes, peripheral neurovascular disease, malignant tumor; preoperative $\mathrm{Hb}<100 \mathrm{~g} / \mathrm{L}$. The duration of postoperative follow-up in this study was 3 months.

\section{Randomization and trial intervention}

Recruited patients were randomly divided into three groups using sealed envelopes in a 1:1:1 ratio opened before surgery. All the surgeries were performed by two senior surgeons in the standard way, using a midline skin incision and a standard medial parapatellar approach. All the included patients received TXA using the same strategy: intravenous TXA was applied $5 \mathrm{~min}$ before incision $(1 \mathrm{~g})$ and $3(1 \mathrm{~g})$ and $6(1 \mathrm{~g})$ hours later after the procedure (3g TXA intravenously in total). One gram of topical TXA in $100 \mathrm{ml}$ of normal saline solution was irrigated in the wound after implantation of the components. During the procedure, in the group A (tourniquet group), patients receiving a full-time tourniquet during the whole procedure. In the group $\mathbf{B}$ (non-tourniquet group), TKA was performed without a tourniquet during the whole procedure. In the group C (tourniquet in cementation group), tourniquet was inflated before prosthesis placement and deflated after cement hardened. The tourniquet (VBM, Germany) was applied in $100 \mathrm{mmHg}$ above systolic blood pressure. Controlled hypotension technique was applied in all operations, in which the systolic pressure was controlled in $90-100 \mathrm{mmHg}$ and the diastolic pressure was in $50-$ $60 \mathrm{mmHg}$.

All the patients received the same prosthesis, a posterior-stabilized fixed bearing P.F.C TKA (DePuy, Warsaw, IN, USA). A total amount of $40 \mathrm{~g}$ of bone cement (Smartest GMV Endurance, DePuy, Blackpool, England) was used for all patients.

\section{Postoperative management}

Intra-articular drainage was applied in every patient and removed in the next morning (within $24 \mathrm{~h}$ after the operation). $0.3 \mathrm{ml}$ (3000 IU) low molecular weight heparin (LMWH) was started $8 \mathrm{~h}$ postoperatively and repeated at $24 \mathrm{~h}$ intervals in the subsequent days while in hospital. After discharged, $10 \mathrm{mg}$ active direct factor Xa inhibitor (Rivaroxaban, Xarelto, Bayer Healthcare) was administrated orally once a day and lasted for 2 weeks after operation. Every patient received the same standardized 
postoperative pain control strategy [9]. Hemoglobin and hematocrit levels were determined on the first and third days after surgery. Active isometric quadriceps and initiative straight-leg raising motion was started just after surgery. Full weight-bearing was permitted since $24 \mathrm{~h}$ postoperatively.

\section{Clinical evaluation}

Clinical evaluation included blood loss evaluation and knee rehabilitation measurement. Perioperative blood loss, drainage volume, and total blood loss (calculated using the modified Gross formula [10]) were determined. The blood transfusion rate was also documented. The use of blood transfusions was standardized, which the hemoglobin concentration was $<70 \mathrm{~g} / \mathrm{L}$ or a patient developed any anemia-related organ dysfunction. Knee pain score, using the visual analogue scale (VAS) method, was documented on the first and third day after surgery. In order to determine whether tourniquet application increase inflammatory reaction and reduce the rehabilitation process after surgery, inflammatory and muscle injury factors (CRP, ESR, IL-6, and CK), range of motion, HSS score were also determined. Furthermore, the length of the postoperative hospital stay and postoperative complications were determined.

\section{Radiological evaluation}

On the first postoperative day, a standard digital anteroposterior and lateral radiograph of the operated knee was taken, which was used to determine the component position. Furthermore, in order to get accurate data of the cement mantle, all patients received digital linear tomosynthesis (DTS) examination in a standard way $[11,12]$. DTS showed greater contrast than conventional DR (Fig. 1a). It gives good results independent of the type of metal and shows good results for the removal of noise artifacts. The effectiveness of this method in enhancing the visibility of a cement mantle was quantified in terms of the signal-to-noise ratio (SNR) and removal of ghosting artifacts in a prosthesis patient. After examination, two radiologists, who blinded whether a tourniquet was used, measured the thickness of the cement mantle independently within the local picture archiving and communication system (PACS). Measurements were performed in four zones based on the Knee Society scoring system and previous surgeons' experience (Fig. 1b) [7, 13]. Cement mantle thickness was measured only in the tibial baseplate and the results were recorded in centimeters with two decimal [7]. The results of mantel thickness in four zones and total cumulated thickness were compared among groups, respectively.

\section{Statistical analysis}

The statistical analysis was the same as our previous RCT study [14]. The distribution of potential confounders among the study groups and the outcomes were assessed with summary statistics, including the means and standard deviations for quantitative data and the frequencies and percentages for qualitative data. The continuous variables were compared using a one-way analysis of variance between the two groups and the categorical variables were compared using the Pearson chi-square test. The level of statistical significance was set at $P<0.05$. The statistical analysis was performed using SPSS software (version 13.0; SPSS Inc., Chicago, IL, USA).

\section{Results}

Patients

One hundred seventy four patients were diagnosed with end-stage osteoarthritis and scheduled to have TKA in
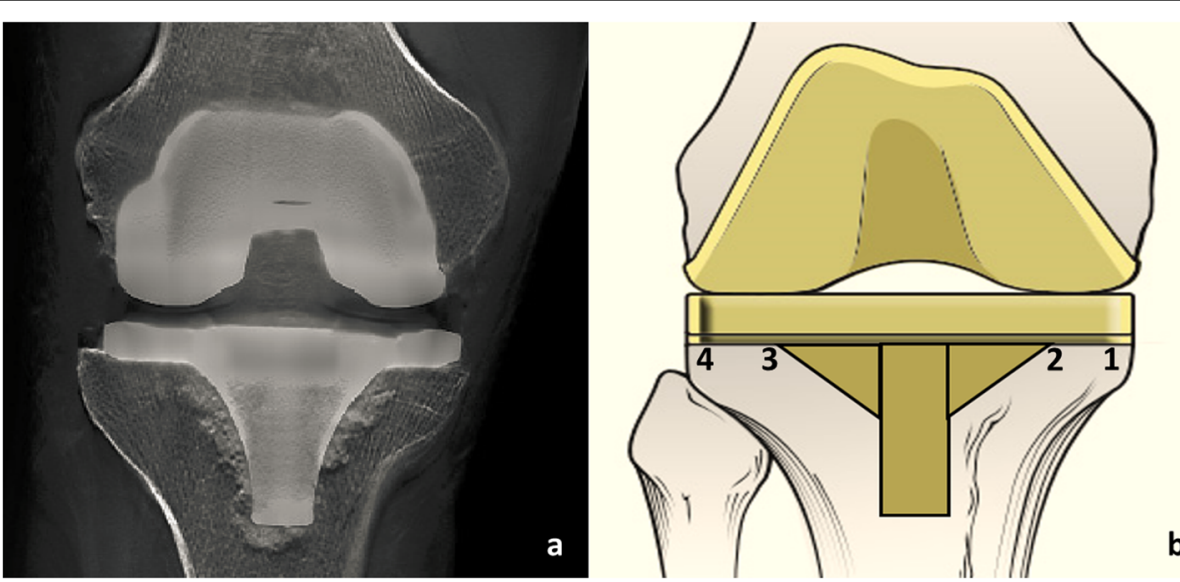

Fig. 1 All patients received digital linear tomosynthesis (DTS) examiniation to measure bone cement mantle thickness. The measurement was performed based on the Knee Society scoring system. a. The radiographic film of digital linear tomosynthesis (DTS) examination, which showed better contrast than conventional DR film. b mantle thickness was measured in tibial baseplate based on the four zones 
our hospital. Twenty four patients were not approached for multiple reasons: 14 were ineligible according to our criteria, and 10 declined to participate in the study (Fig. 2). The remaining 150 eligible participants formed the study cohort, with 50 randomized to each group. The three groups were similar at baseline with no significant difference among the groups (Table 1).

\section{Surgical results and complications}

Table 2 reveals the results of perioperative assessment results. The mean surgical time in the group A, group B, and group $C$ were $76.70 \mathrm{~min}, 79.30 \mathrm{~min}$, and $80.70 \mathrm{~min}$, respectively, with no significant intergroup differences. The mean tourniquet time in the group A was 61.00 min, which was significantly longer than those in group $\mathrm{C}$ (10.20 min).

No DVT, PE, or fracture occurred among the groups at the end of follow up. Two cases in the group $\mathrm{A}$ and 1 case in the group $\mathrm{C}$ were diagnosed with calf muscular venous thrombosis by color Doppler ultrasonography during hospitalization with no specific treatment. No lower extremities swelling was found and treated with routine prophylactic anticoagulation treatment. One case in the group A suffered from wound superficial cellulitis, cured with antibiotics and dressing changes.

\section{Blood loss and transfusion}

The mean intraoperative blood loss in the group A, group $\mathrm{B}$, and group $\mathrm{C}$ were $70.20 \mathrm{ml}, 159.80 \mathrm{ml}$, and $137.40 \mathrm{ml}$, respectively, with significant intergroup differences. The mean drain volume was $218.26 \mathrm{ml}$ in the group A, $77.80 \mathrm{ml}$ in the group B, and $101.40 \mathrm{ml}$ in the group C. Group A resulted in significantly higher drain volume compared with the other two groups. The mean hemoglobin and hematocrit was $109.32 \mathrm{~g} / \mathrm{L}, 0.33 \%$ in the group $\mathrm{A}, 104.06 \mathrm{~g} / \mathrm{L}, 0.32 \%$ in group $\mathrm{B}$, and $104.84 \mathrm{~g} / \mathrm{L}$, $0.32 \%$ in the group $C$, with no significant intergroup differences. Calculated by Gross formulation, the mean total blood loss in the group A, group B, and group C were $611.02 \mathrm{ml}, 695.10 \mathrm{ml}$, and $666.88 \mathrm{ml}$, respectively, with no significant intergroup differences. No patient received a transfusion in any group.

\section{Inflammatory factor assessment}

The mean post. CRP, ESR, and IL-6 was $126.65 \mathrm{mg} / \mathrm{L}$, $70.64 \mathrm{~mm} / \mathrm{L}$, and $133.67 \mathrm{pg} / \mathrm{ml}$ in group $\mathrm{A}, 79.08 \mathrm{~mm} / \mathrm{L}$, $45.02 \mathrm{~mm} / \mathrm{L}$, and $77.29 \mathrm{pg} / \mathrm{ml}$ in group $\mathrm{B}, 105.21 \mathrm{mg} / \mathrm{L}$, $66.18 \mathrm{~mm} / \mathrm{L}$, and $106.75 \mathrm{pg} / \mathrm{ml}$ in group C. Group B resulted in significantly less CRP, ESR, and IL-6 levels compared with the other two groups. There was no difference between the group A and group $\mathbf{C}$ in terms of these three factors. The mean post. CK was $226.66 \mathrm{IU} / \mathrm{L}$ in group A, $158.08 \mathrm{IU} / \mathrm{L}$ in group B, and $106.92 \mathrm{IU} / \mathrm{L}$ in group C, respectively. Group A showed significantly higher CK levels compared to the other two groups.

\section{Post. Recovery and rehabilitation}

The mean length of hospital stay in the group A, group $\mathrm{B}$, and group $\mathrm{C}$ was $4.42,3.50$, and 3.70 , respectively, with significant intergroup differences.

The mean range of motion at POD 3 days and 3 months were $100^{\circ}$ and $111^{\circ}$ in the group A, $104^{\circ}$ and

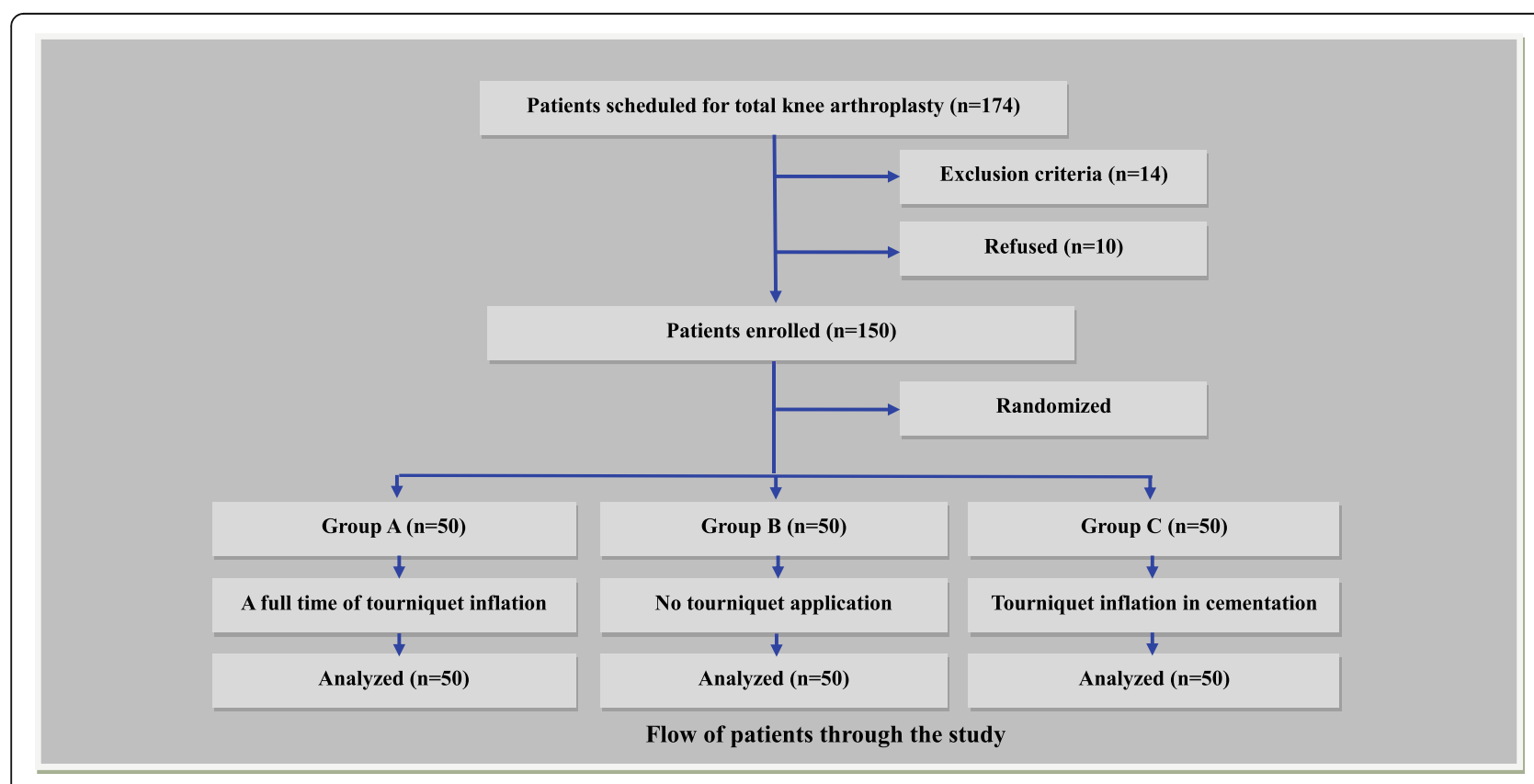

Fig. 2 Flow of patients through the study 
Table 1 Baseline characteristics of the study population

\begin{tabular}{|c|c|c|c|c|}
\hline Variable & $\begin{array}{l}\text { Group A } \\
\text { (Tourniquet group) } \\
(N=50)\end{array}$ & $\begin{array}{l}\text { Group B } \\
\text { (Non-tourniquet group) } \\
(N=50)\end{array}$ & $\begin{array}{l}\text { Group } C \\
\text { (Tourniquet in cementation group) } \\
(N=50)\end{array}$ & $p$ value* \\
\hline \multicolumn{5}{|l|}{ Demographic characteristics } \\
\hline Age (yr) & $68.44 \pm 6.80$ & $68.00 \pm 7.11$ & $68.66 \pm 7.27$ & 0.89 \\
\hline Male sex (\%) & $7(14 \%)$ & $8(16 \%)$ & $7(14 \%)$ & - \\
\hline Weight (kg) & $64.39 \pm 8.16$ & $62.66 \pm 10.44$ & $63.64 \pm 11.27$ & 0.67 \\
\hline Height (cm) & $153.88 \pm 21.49$ & $157.06 \pm 6.74$ & $156.52 \pm 7.08$ & 0.46 \\
\hline $\mathrm{BMI}\left(\mathrm{kg} / \mathrm{m}^{2}\right)$ & $26.13 \pm 2.63$ & $25.34 \pm 3.61$ & $25.88 \pm 3.51$ & 0.42 \\
\hline $\begin{array}{l}\text { ASA status }|-\||| \geq\|| \mid \\
\text { (No. of patients) }\end{array}$ & $35 / 15$ & $38 / 12$ & $36 / 14$ & - \\
\hline \multicolumn{5}{|l|}{ Diagnosis } \\
\hline Primary OA & 50 & 50 & 50 & - \\
\hline \multicolumn{5}{|l|}{ Preoperative laboratory values } \\
\hline Preo. Hemoglobin (g/dl) & $134.84 \pm 12.25$ & $132.18 \pm 15.10$ & $129.50 \pm 14.98$ & 0.17 \\
\hline Preo. Hematocrit $(L / L)$ & $0.41 \pm 0.04$ & $0.41 \pm 0.04$ & $0.40 \pm 0.04$ & 0.82 \\
\hline Preo. CRP $\left(10^{9} / \mathrm{L}\right)$ & $3.94 \pm 3.13$ & $3.29 \pm 2.00$ & $3.79 \pm 2.30$ & 0.41 \\
\hline Preo. ESR (mm/L) & $21.88 \pm 12.59$ & $24.08 \pm 13.21$ & $28.32 \pm 16.87$ & 0.08 \\
\hline Preo. IL-6 (pg/ml) & $4.28 \pm 2.04$ & $3.40 \pm 2.19$ & $3.76 \pm 2.27$ & 0.13 \\
\hline Preo. CK (IU/L) & $81.52 \pm 29.89$ & $85.02 \pm 39.71$ & $74.06 \pm 31.36$ & 0.26 \\
\hline \multicolumn{5}{|l|}{ Preoperative knee function } \\
\hline VAS score (points) & $7.28 \pm 0.97$ & $7.32 \pm 0.95$ & $7.16 \pm 0.87$ & 0.67 \\
\hline Range of motion & $94 \pm 16$ & $97 \pm 20$ & $95 \pm 14$ & 0.67 \\
\hline HHS score (points) & $56.64 \pm 4.24$ & $55.10 \pm 4.62$ & $56.74 \pm 4.04$ & 0.11 \\
\hline
\end{tabular}

Abbreviations: OA, osteoarthritis; CRP, C-reaction protein; ESR, erythrocyte sedimentation rate; IL-6, interleukin-6; CK, creatine kinase; HSS score, hospital of special surgery score

*The $p$ value represents the result of one-way analysis of variance for independent means for continuous variables or the chi-square test for independent proportions that included the three groups

$111^{\circ}$ in the group $\mathrm{B}$, and $103^{\circ}$ and $112^{\circ}$ in the group $\mathrm{C}$, respectively. Group A resulted in a significantly lower range of motion at POD 3 days compared with the other two groups. However, no significant difference was found in POD 3 months in terms of a range of motion at POD 3 months.

VAS pain scores at 1 and 3 days after operation were 3.70 and 2.28 in the group A, 3.08 and 1.86 in the group $\mathrm{B}$, and 3.44 and 1.80 in the group $\mathrm{C}$, respectively. Group A showed significantly higher pain points at both the two postoperative time points compared with the other two groups.

The mean HSS score was 83.96 in the group A, 84.16 in the group B, and 83.94 in the group C, respectively, with no significant difference among the groups.

\section{Bone cement mantle thickness assessment}

The bone cement mantle thickness in the three groups in different zones was ranged from $0.26 \mathrm{~cm}$ to $0.33 \mathrm{~cm}$ (Table 3). No significant difference was found among the three groups in each zone. The average bone cement mantle thickness was $0.28 \mathrm{~cm}$ in the group A, $0.29 \mathrm{~cm}$ in the group $B$, and $0.29 \mathrm{~cm}$ in the group $C$, which also showed no significant difference.

\section{Discussion}

The most important finding of our present study was that, with the advantage of TXA combined application, performing a tourniquetless TKA may result in less soft tissue injury and rapid postoperative recovery, without increasing blood loss and complication risk.

Table 4 summarized the previous reported results of different tourniquet application strategy in TKA since 2010. According to the survey by AAHKS, approximately $95 \%$ of surgeons used a tourniquet in TKA routinely [15]. Advocates of tourniquet believed that the use of a tourniquet is the most effective method for bleeding control. However, opponents of tourniquet pointed out that the application of a tourniquet shows no obvious benefit on the total blood loss because hidden blood loss is a significant portion of total blood loss and should not be ignored [16]. In our study, we found intraoperative blood loss in patients of the tourniquet group was significantly less than patients in non-tourniquet and 
Table 2 perioperative characteristics of patients utilizing tourniquet or not

\begin{tabular}{|c|c|c|c|c|}
\hline Variable & $\begin{array}{l}\text { Group A } \\
\text { (Tourniquet group) } \\
(N=50)\end{array}$ & $\begin{array}{l}\text { Group B } \\
\text { (Non-tourniquet group) } \\
(N=50)\end{array}$ & $\begin{array}{l}\text { Group C } \\
\text { (Tourniquet in cementation) } \\
\text { group }(N=50)\end{array}$ & $p$ value ${ }^{*}$ \\
\hline \multicolumn{5}{|l|}{ Surgical information } \\
\hline Surgical time & $76.60 \pm 8.72$ & $79.30 \pm 8.21$ & $80.70 \pm 10.15$ & 0.07 \\
\hline Tourniquet time & $61.00 \pm 6.55^{b}$ & - & $10.20 \pm 1.92$ & $<0.05$ \\
\hline Intraoperative blood loss (ml) & $70.20 \pm 36.62^{a, b}$ & $159.80 \pm 28.32 \&$ & $137.40 \pm 38.16$ & $<0.05$ \\
\hline Drain volume (ml) & $218.26 \pm 102.37^{a, b}$ & $77.80 \pm 26.05$ & $101.40 \pm 35.91$ & $<0.05$ \\
\hline Total blood loss (ml) & $611.02 \pm 299.22$ & $695.10 \pm 333.43$ & $666.88 \pm 485.03$ & 0.53 \\
\hline No. of patients given transfusion (\%) & 0 & 0 & 0 & - \\
\hline \multicolumn{5}{|l|}{ Postoperative laboratory values } \\
\hline Postop. Hemoglobin (g/L) & $109.32 \pm 14.82$ & $104.06 \pm 15.17$ & $104.84 \pm 13.78$ & 0.15 \\
\hline Postop. Hematocrit (\%) & $0.33 \pm 0.04$ & $0.32 \pm 0.05$ & $0.32 \pm 0.04$ & 0.32 \\
\hline Post. CRP (mg/L) & $126.65 \pm 67.41^{\mathrm{a}}$ & $79.08 \pm 53.05 \&$ & $105.21 \pm 26.36$ & $<0.05$ \\
\hline Post. ESR (mm/L) & $70.64 \pm 11.96^{\mathrm{a}}$ & $45.02 \pm 10.98 \&$ & $66.18 \pm 28.27$ & $<0.05$ \\
\hline Post. IL-6 (pg/ml) & $133.67 \pm 46.25^{\mathrm{a}}$ & $77.29 \pm 80.65 \&$ & $106.75 \pm 108.09$ & $<0.05$ \\
\hline Post. CK (IU/L) & $226.66 \pm 103.03^{\mathrm{a}}$ & $158.08 \pm 100.72$ & $196.92 \pm 93.94$ & $<0.05$ \\
\hline Post. Length of hospital stay & $4.42 \pm 1.23^{a, b}$ & $3.50 \pm 0.54 \&$ & $3.70 \pm 0.91$ & $<0.05$ \\
\hline Post. Range of motion (3 days) & $100 \pm 5^{a, b}$ & $104 \pm 6$ & $103 \pm 6$ & $<0.05$ \\
\hline Post. Range of motion (3 months) & $111 \pm 9$ & $111 \pm 8$ & $112 \pm 9$ & 0.90 \\
\hline Post. VAS ( 1 day) & $3.70 \pm 1.18^{\mathrm{a}}$ & $3.08 \pm 1.05$ & $3.44 \pm 1.11$ & 0.02 \\
\hline Post. VAS (3 days) & $2.28 \pm 0.61^{\mathrm{a}}$ & $1.80 \pm 0.53$ & $1.86 \pm 0.67$ & $<0.05$ \\
\hline Post. HSS score & $83.96 \pm 3.24$ & $84.16 \pm 2.92$ & $83.94 \pm 3.71$ & 0.94 \\
\hline
\end{tabular}

*The $p$ value represents the result of one-way analysis of variance for independent means for continuous variables that included the three groups. $P$ values with statistical significance are in bold print. ${ }^{\text {a }}$ Significantly different from the non-tourniquet group

${ }^{\mathrm{b}}$ Significantly different from the tourniquet in cementation group. \& Significantly different from the tourniquet in cementation group

tourniquet in cementation groups. However, the volume measured in the surgical drain was significantly higher in the tourniquet group. After calculated by Gross formula, no obvious difference was found among the three groups with regard to the total blood loss.

TXA application plays an important role in reducing blood loss for patients receiving TKA without a tourniquet, especially for the combined application strategy. Huang et al. [17] from our institution has proved that TKA patients treated with multiple doses of intravenous and topical TXA had less hidden blood loss, better knee function recovery, and better early satisfaction than controlled patients. Multiple doses of intravenous TXA application can prevent systemic plasminogen activation and delay fibrinolysis, which can result in intraoperative blood loss and postoperative hidden blood loss reduction [18]. Compared with intravenous TXA, topical application can provide a maximum concentration of TXA at the bleeding site, lower TXA absorption, reduce limb swelling, and improve wound-healing $[19,20]$. In our study, although the intraoperative blood loss and drain volume were different, there was no significant difference among

Table 3 Bone cement mantle thickness measurement (cm)

\begin{tabular}{|c|c|c|c|c|}
\hline Variable & $\begin{array}{l}\text { Group A } \\
\text { (Tourniquet group) } \\
(N=50)\end{array}$ & $\begin{array}{l}\text { Group B } \\
\text { (Non-tourniquet group) } \\
(N=50)\end{array}$ & $\begin{array}{l}\text { Group } C \\
\text { (Tourniquet in cementation group) } \\
(N=50)\end{array}$ & $p$ value* \\
\hline Zone 1 & $0.26 \pm 0.07$ & $0.28 \pm 0.03$ & $0.27 \pm 0.04$ & 0.17 \\
\hline Zone 2 & $0.26 \pm 0.04$ & $0.26 \pm 0.04$ & $0.26 \pm 0.03$ & 0.24 \\
\hline Zone 3 & $0.33 \pm 0.07$ & $0.33 \pm 0.06$ & $0.32 \pm 0.08$ & 0.84 \\
\hline Zone 4 & $0.29 \pm 0.06$ & $0.30 \pm 0.06$ & $0.29 \pm 0.05$ & 0.54 \\
\hline Average & $0.28 \pm 0.06$ & $0.29 \pm 0.07$ & $0.29 \pm 0.06$ & 0.56 \\
\hline
\end{tabular}

*The $p$ value represents the result of one-way analysis of variance for independent means for continuous variables that included the three groups

$P$ values with statistical significance are in bold print 


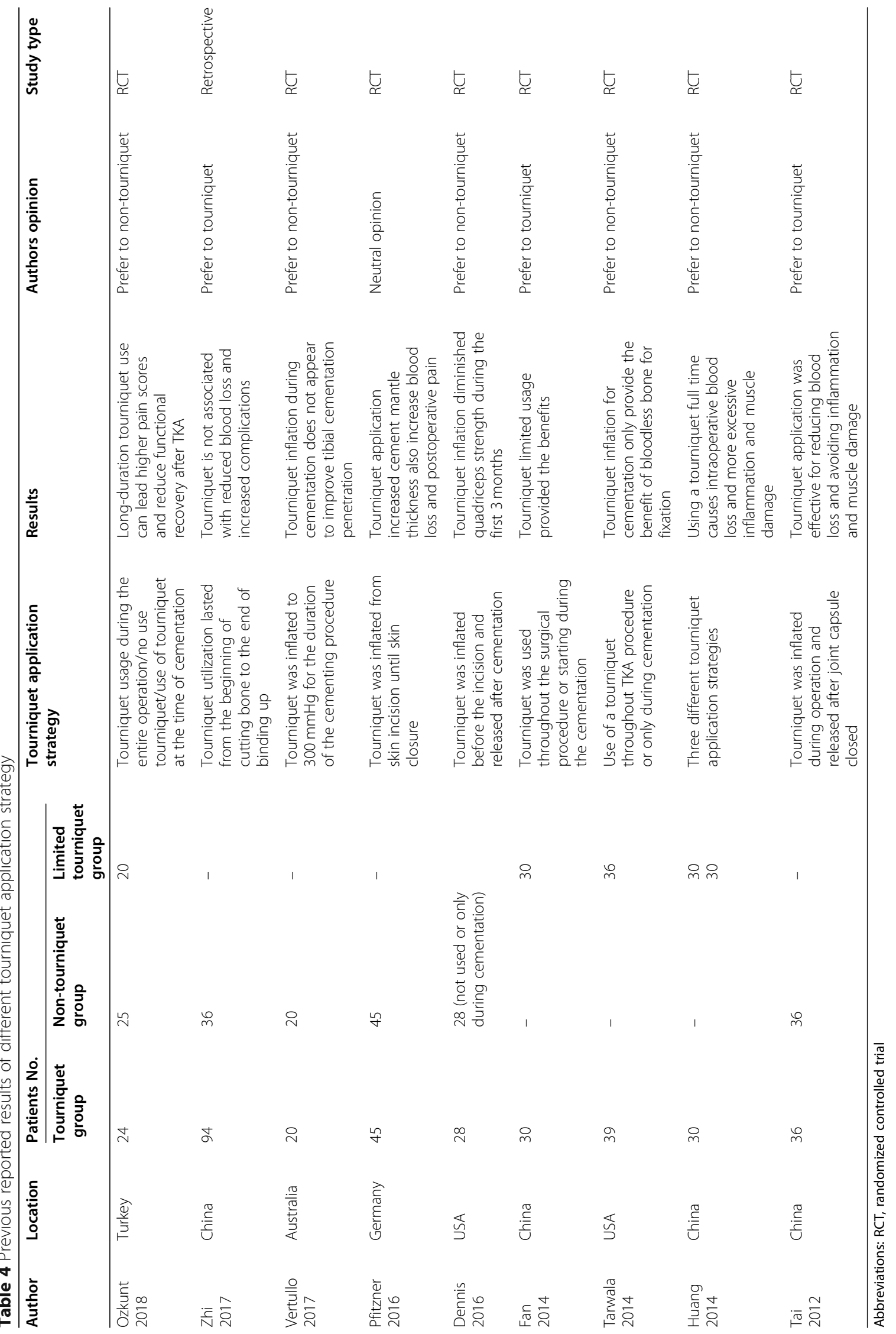


the three groups in terms of total blood loss. Also, no patient received a transfusion and no VTE complication occurred after TKA. For consideration of TXA advantages, we believe that tourniquet is not necessary when performing a TKA, because the most advantage of tourniquet in reducing blood loss has disappeared [8].

Tourniquet inflation, which is an obvious cause of perioperative hypoxia, can cease blood flow and damage soft tissue by acute ischemia-reperfusion [21]. Platelet, leukocyte, and endothelium activities as well as their interactions were demonstrated to enhance during the perioperative period of TKA, and tourniquet inflation could exaggerate these responses [22]. Lesser tourniquet time is much better for tissue oxygenation and early wound dryness [23]. Our result showed, the soft tissue damage indicators, including CRP, ESR, IL-6, and CK, were significantly lower in patients without tourniquet compared with those in the other two tourniquet groups. Furthermore, VAS scores ( 1 and 3 days post.), range of motion on 3 days postoperatively and length of hospital stay in tourniquetless group also showed better results than the other two groups. Our results were consistent with other previous clinical studies. Ledin et al. [24] performed a randomized RSA study involving 50 patients and found tourniquet use could cause more postoperative pain and less range of motion. A recent RCT by Dennis et al. [6] demonstrated patients who underwent TKA using a tourniquet had diminished quadriceps strength during the first 3 months after TKA. A meta-analysis by Zhang et al. [1] demonstrated that TKA with a tourniquet might hinder patients' early postoperative rehabilitation exercise. With the current improvements in surgical techniques and TXA usage strategy, tourniquet application during TKA procedure may decelerate the rapid track recovery rate and increase complication rates, and gradually become unnecessary.

Aseptic loosening is one of the most frequent causes of TKA revision $[25,26]$. In order to achieve long term implant stability and survival, creating a clean and blood-poor bone surface for cement penetration is one of the important reasons for tourniquet application. Previous studies have demonstrated that implant stability depends on cement penetration and mantle thickness [27]. Some still worried about the absence of tourniquet might affect cement penetration and implants fixation [7]. However, as the surgical technique develops, some recent studies demonstrated that tourniquet inflation during a TKA procedure does not appear to improve implant cementation penetration or fixation [23, 28]. Our present study showed that there was no significant difference among the three groups in four zones of tibial cement mantle thickness. In our opinion, TXA application and controlled hypotension are effective methods to reduce blood loss and provide a blood-free bone-cement interface, instead of using a tourniquet. Furthermore, to our knowledge, DTS was first applied to determine cement mantle thickness in TKA patients. This new radiographic technique provides good contrast, enhance the visibility of a cement mantle, and remove ghost artifacts in prosthesis patients, which will be more widely used in the joint arthroplasty field [11].

This study has some limitations. First, the 3 months duration of follow-up in the present study might have concealed different long-term outcomes for the tourniquet usage. However, tourniquet mainly influences the early rehabilitation of a TKA patient, without a longterm effect. Second, in order to predict implant survival, we only determined the cement mantle thickness. However, although mantle thickness can influence implant fixation, the relationship between mantle thickness and implant survival is still in controversy. Finally, the study population was small. For the low incidence of postoperative complications, such as infection, DVT, and PE, a larger sample size might be better to find the statistical difference among the groups.

\section{Conclusions}

In conclusion, compared with the other two tourniquet groups, the absence of tourniquet did not appear to affect blood loss and cement penetration in TKA patients. Furthermore, less inflammation reaction and better knee function can be achieved without a tourniquet. For consideration of the effectiveness and safety of tourniquet application, we recommend no longer use a tourniquet in primary TKA when TXA is administrated. More highquality studies with larger number of participants and longer follow-up are needed to confirm the effect of tourniquet on clinical outcomes of knee OA patients treated with TKA.

\section{Acknowledgments \\ The authors wish to thank Dr. Kai Liao and Dr. Zhixuan Liu from dept. radiology, West China Hospital for the radiological examination and results evaluation.}

\section{Authors' contributions}

Zeng Yi and Shen Bin designed the study. Li Yan, Si Haibo, and Wu Yuangang analyzed the data. Zeng Yi drafted the article. Li Mingyang and Liu Yuan undertook the statistical analyses. Li Yan performed the radiographic analysis. All authors contributed to the interpretation of the results, and final approval of the article.

\section{Authors' information}

Not applicable.

\section{Funding}

This study was funded by National Clinical Research Center for Geriatrics, West China Hospital, Sichuan University (Z20191008). This study was also supported by the Science and Technology Department of Sichuan Province (No. 2018HH0141) and the Health Department of Chengdu city, Sichuan Province (No. 18ZD016). 


\section{Availability of data and materials}

Request for details in the study dataset can be submitted to the corresponding author. Human subject protection requirements, appropriate data privacy as well as institutional requirements must be met.

\section{Ethics approval and consent to participate}

As stated in the Methods section, the study was approved by the Clinical Trials and Biomedical Ethics Committee of West China Hospital (No. 201302007) and all methods were carried out in accordance with relevant guidelines and regulations (Declaration of Helsinki). All participants signed a written informed consent.

\section{Consent for publication}

Not applicable.

\section{Competing interests}

The authors declare no competing interests.

\section{Author details}

'Department of Orthopaedic Surgery, Orthopaedic Research Institue, and National Clinical Research Center for Geriatrics, West China Hospital, Sichuan University, Sichuan Province, Chengdu 610041, China. ${ }^{2}$ Department of Orthopaedic Surgery, West China Hospital, Sichuan University, 37\# Guoxue Road, Chengdu 610041, People's Republic of China. ${ }^{3}$ Department of Radiology, West China Hospital, West China Medical School, Sichuan University, Sichuan Province, Chengdu 610041, China.

Received: 20 September 2020 Accepted: 11 January 2021

Published online: 31 January 2021

\section{References}

1. Zhang W, Li N, Chen S, Tan Y, Al-Aidaros M, Chen L. The effects of a tourniquet used in total knee arthroplasty: a meta-analysis. J Orthop Surg. 2014:9:13

2. Goel R, Rondon AJ, Sydnor K, Blevins K, O'Malley M, Purtill JJ, Austin MS. Tourniquet use does not affect functional outcomes or pain after total knee arthroplasty: a prospective, double-blinded, randomized controlled trial. J Bone Joint Surg Am. 2019;101:1821-8.

3. Cai DF, Fan $\mathrm{QH}$, Zhong HH, Peng S, Song $\mathrm{H}$. The effects of tourniquet use on blood loss in primary total knee arthroplasty for patients with osteoarthritis: a meta-analysis. J Orthop Surg Res. 2019;14:348.

4. Li Z, Liu D, Long G, Ke G, Xiao A, Tang P, Dong J. Association of tourniquet utilization with blood loss, rehabilitation, and complications in Chinese obese patients undergoing total knee arthroplasty: a retrospective study. Medicine (Baltimore). 2017:6:e9030.

5. Kerkhoffs G, Servien E, Dunn W. The influence of obesity on the complications rate and outcomes of total knee arthroplasty: a meta-analysis and systematic literature review. J Bone Joint Surg Am. 2012;94:1839-44.

6. Dennis DA, Kittelson AJ, Yang CC, Miner TM, Kim RH, Stevens-Lapsley JE. Does tourniquet use in TKA affect recovery of lower extremity strength and function? A randomized trial. Clin Orthop Relat Res. 2016:474:69-77.

7. Pfitzner T, von Roth P, Voerkelius N, Mayr H, Perka C, Hube R. Influence of the tourniquet on tibial cement mantle thickness in primary total knee arthroplasty. Knee Surg Sports Traumatol Arthrosc. 2016;24:96-101.

8. Brusalis CM, Bostrom MPG, Richardson SS. Has tranexamic acid in total knee arthroplasty made tourniquet obsolete? HSS J. 2018;14:338-40.

9. Shen B, Wen X, Liao R, Qu T, Qu X, Cao L, Yan S, Liao W, Qian Q, Zhengan Z, Tian H, Qian W, Yuan H, Liu B, Huang Y, Wang K, Sun X, Qiu G, Pei F. Expert consensus in enhanced recovery after total hip and knee arthroplasty in China: pain and sleep management. Chin J Bone Joint Surg. 2016:9:91-7.

10. Gross JB. Estimating allowable blood loss: corrected for dilution. Anesthesiology. 1983;58:277-80

11. Gomi T, Hirano H. Clinical potential of digital liner tomosynthesis imaging of total joint arthroplasty. J Digit Imaging. 2008;21:312-22.

12. Gomi T, Hirano H, Umedo T. Evaluation of the X-ray digital linear tomosynthesis reconstruction processing method for metal artifact reduction. Comput Med Imaging Graph. 2009;33:267-74.

13. Kopec M, Milbrandt JC, Duellman T, Mangan D, Allan DG. Effect of hand packing versus cement gun pressurization on cement mantel in total knee arthroplasty. Can J Surg. 2009;52:490-4.
14. Yi Z, Bin S, Jing Y, Zongke Z, Pengde K, Fuxing P. Tranexamic acid Administration in Primary Total hip Arthroplasty: a randomized controlled trial of intravenous combined with topical versus single-dose intravenous administration. J Bone Joint Surg Am. 2016;98:983-91.

15. Berry DJ, Bozic KJ. Current practice patterns in primary hip and knee arthroplasty among members of the American association of hip and knee surgeons. J Arthroplasty. 2010;25:2-4.

16. Foss NB, Kehlet $\mathrm{H}$. Hidden blood loss after surgery for hip fracture. J Bone Joint Surg Br. 2006;88:1053-9.

17. Huang Z, Xie X, Li L, Huang Q, Ma J, Shen B, Kraus VB, Pei F. Intravenous and topical tranexamic acid alone are superior to tourniquet use for primary total knee arthroplasty: a prospective, randomized controlled trial. J Bone Joint Surg Am. 2017:99:2053-61.

18. Wu YG, Zeng Y, Hu QS, Bao XC, Xiong HZ, Shen B. Tranexamic acid plus low-dose epinephrine reduces blood loss in total knee arthroplasty: a systematic review and meta-analysis. Orthop Res. 2018;8:287-95.

19. Chimento GF, Huff T, Ochsner JL Jr, Meyer M, Brandner L, Babin S. An evaluation of the use of topical tranexamic acid in total knee arthroplasty. J Arthroplasty. 2013;28:74-7.

20. Wong J, Abrishami A, El Beheiry H, Mahomed NN, Roderick Davey J, Gandhi R, Syed KA, Muhammad Ovais Hasan S, De Silva Y, Chung F. Topical application of tranexamic acid reduces postoperative blood loss in total knee arthroplasty: a randomized, controlled trial. J Bone Joint Surg Am. 2010:92:2503-13.

21. Clarke MT, Longstaff L, Edwards D, Rushton N. Tourniquet-induced wound hypoxia after total knee replacement. J Bone Joint Surg Br. 2001;83:40-4.

22. Kageyama K, Nakajima Y, Shibasaki M, Hashimoto S, Mizobe T. Increased platelet, leukocyte, and endothelial cell activity are associated with increased coagulability in patients total knee arthroplasty. J Thromb Haemost. 2007;5:738-45.

23. Butt U, Ahmad R, Aspros D, Bannister GC. Factors affecting wound ooze in total knee replacement. Ann R Coll Surg Engl. 2011;93:54-6.

24. Ledin H, Aspenberg P, Good L. Tourniquet use in total knee replacement does not improve fixation, but appears to reduce final range of motion. Acta Orthop. 2012;83:499-503.

25. Postler A, Lutzner C, Beyer F, Tille E, Lutzner J. Analysis of total knee arthroplasty revision causes. BMC Musculoskelet Disord. 2018;19:55.

26. Pietrzak J, Common H, Migaud H, Pasquier G, Girard J, Putman S. Have the frequency of and reasons for revision total knee arthroplasty changed since 2000? Comparison of two cohorts from the same hospital: 255 cases (2013-2016) and 68 cases (1991-1998). Orthop Traumatol Surg Res. 2019;105:639-45.

27. Peters CL, Craig MA, Mohr RA, Bachus KN. Tibial component fixation with cement: full- versus surface-cementation techniques. Clin Orthop Relat Res. 2003;409:158-68.

28. Vertullo CJ. Nagarajan M. is cement penetration in TKR reduced by not using a tourniquet during cementation? A single blinded, randomized trial. J Orthop Surg (Hong Kong). 2017;25:1-7.

\section{Publisher's Note}

Springer Nature remains neutral with regard to jurisdictional claims in published maps and institutional affiliations.

Ready to submit your research? Choose BMC and benefit from:

- fast, convenient online submission

- thorough peer review by experienced researchers in your field

- rapid publication on acceptance

- support for research data, including large and complex data types

- gold Open Access which fosters wider collaboration and increased citations

- maximum visibility for your research: over $100 \mathrm{M}$ website views per year

At BMC, research is always in progress.

Learn more biomedcentral.com/submissions 